\title{
Story Mill Hydrology and Water Quality Data [dataset]
}

\section{Author: Lillian Deford}

DOI

http://doi.org/10.15788/M2TG6C

\section{Date uploaded}

August 2016

\section{Description}

This dataset includes all of the data collected and used to analyze the Story Mill hydrology and water quality for the thesis: Hydrologic Influence of Wetland Restoration: the Story Mill Case Study. The objective of this project was to use the data to speculate about the impacts of the wetland restoration that took place on the Story Mill property in Bozeman Montana one year after restoration. Raw data was collected from groundwater wells and surface water gauging stations arranged throughout the site, and includes: water levels, total nitrogen, total phosphorus, nitrate, nitrite, orthophosphate, chloride, sulfate, chloride, $\mathrm{pH}$, and dissolved oxygen. Water levels were collected manually as well as continuously with data loggers - both are included. Weather data obtained from the weather station on the Montana State University Campus is included in this dataset, collected and used with permission by Joseph Shaw. Chemical analysis standard data is also provided, developed for the analysis of ionic constituents, total nitrogen, and total phosphorus. Data is arranged in several different spreadsheets but is designed to be linked and correlated - see the dataset illustration. The Primary analysis software used was $\mathrm{R}$, and all code is provided.

\section{Citations}

Deford L (2016) Story Mill Hydrology and Water Quality Data [dataset]. Montana State University ScholarWorks. http://doi.org/10.15788/M2TG6C. 